\title{
Subtotal Parathyroidectomy
}

National Cancer Institute

\section{Source}

National Cancer Institute. Subtotal Parathyroidectomy. NCI Thesaurus. Code C51594.

Partial excision of the parathyroid gland(s). 